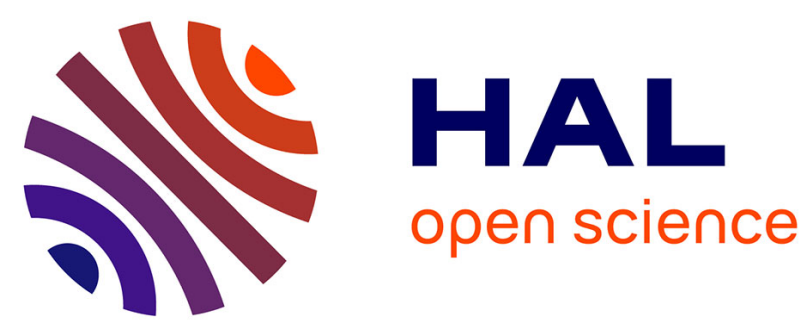

\title{
Effect of freeze-dryer design on heat transfer variability investigated using a 3D mathematical model
}

\author{
B. Scutellà, E. Bourlés, Artemio Plana-Fattori, F. Fonseca, D. Flick, \\ Ioan-Cristian Trelea, S. Passot
}

\section{- To cite this version:}

B. Scutellà, E. Bourlés, Artemio Plana-Fattori, F. Fonseca, D. Flick, et al.. Effect of freeze-dryer design on heat transfer variability investigated using a 3D mathematical model. Journal of Pharmaceutical Sciences, 2018, 107 (8), pp.2098-2106. 10.1016/j.xphs.2018.04.002 . hal-01769104

HAL Id: hal-01769104

https://hal-agroparistech.archives-ouvertes.fr/hal-01769104

Submitted on 17 Apr 2018

HAL is a multi-disciplinary open access archive for the deposit and dissemination of scientific research documents, whether they are published or not. The documents may come from teaching and research institutions in France or abroad, or from public or private research centers.
L'archive ouverte pluridisciplinaire HAL, est destinée au dépôt et à la diffusion de documents scientifiques de niveau recherche, publiés ou non, émanant des établissements d'enseignement et de recherche français ou étrangers, des laboratoires publics ou privés. 
Effect of freeze-dryer design on heat transfer variability investigated using a 3D mathematical model

Authors: B. Scutellà ${ }^{1,2}$, E. Bourlés ${ }^{2}$, A. Plana-Fattori ${ }^{3}$, F. Fonseca ${ }^{1}$, D. Flick ${ }^{3}$, I.C. Trelea ${ }^{1}$, S. Passot $^{1}$

${ }^{1}$ UMR GMPA, AgroParisTech, INRA, Université Paris Saclay, 78850 Thiverval-Grignon, France

${ }^{2}$ GSK Vaccines, Rixensart, Belgium

${ }^{3}$ UMR Ingénierie Procédés Aliments, AgroParisTech, INRA, Université Paris-Saclay, 91300 Massy, France 


\begin{abstract}
In the freeze-drying process, vials located at the border of the shelf usually present higher heat flow rates which in turn result in higher product temperatures than central vials. This phenomenon, named edge vial effect, can result in product quality variability within the same batch of vials and between batches at different scales. Our objective was to investigate the effect of various freeze-dryer design features on the heat transfer variability. A 3D mathematical model previously developed in COMSOL Multiphysics and experimentally validated was used to simulate heat transfer of a set of vials located at the edge and in the centre of the shelf. The design features considered were the loading configurations of the vials, the thermal characteristics of the rail, the walls and the shelves and some relevant dimensions of the drying chamber geometry. The presence of the rail in the loading configuration and the value of the shelf emissivity strongly impacted on the heat flow rates received by the vials. Conversely, the heat transfer was not significantly influenced by modifications of the thermal conductivity of the rail, the emissivity of the walls and by the geometry of the drying chamber. The developed model revealed to be a powerful tool to predict the heat transfer variability between edge and central vials for the cycle development and scale-up and to compare various freeze-dryer design features.
\end{abstract}

Key words: freeze drying/lyophilisation, vaccines, injectables, amorphous, mathematical model, processing 


\section{Introduction}

Nowadays, freeze-drying process is widely used in pharmaceutical industry as essential step for extending the product shelf life of several parenteral drugs and biologicals. Due to the combined use of vacuum and low temperatures, this process is recognized to be a gentle method to convert solutions of heat labile drugs, such as vaccines, into solid forms with sufficient stability for shipping and long-term storage. ${ }^{1,2}$

The objective of designing a freeze-drying cycle is to guarantee a high and consistent product quality within the vial batch and from different batches that could be manufactured in various freeze-dryers. ${ }^{3-6}$ Since the product quality is known to be highly correlated to the product temperature, the product thermal history should be as similar as possible between vials and between cycles run in pilot and commercial scale. ${ }^{4}$ However, product temperature profile depends not only on the process operating conditions (i.e., chamber pressure and shelf temperature) but also on the position-dependent heat transfer. ${ }^{7-9}$ Vials on the shelf may be roughly divided into two groups: vials located at the periphery of the shelf (named "edge vials") and vials located in the center (named "central vials"). Edge vials usually receive an additional heat flow rate and present a product temperature higher than central vials up to $4{ }^{\circ} \mathrm{C} .{ }^{7-10}$ This heat transfer variability, known as the "edge vial effect", could be a serious problem in process design if not accurately predicted, since edge vials are likely to collapse if the product is processed at a temperature close to the limit one (e.g., glass transition temperature for amorphous products). ${ }^{7}$ Mathematical models of heat transfer during freeze-drying can be used to predict heat flow rates in vials differently located on the shelf and to investigate the mechanisms responsible for the heat transfer variability between edge and central vials and to predict the edge vial effect.

Table 1 summarizes the characteristics of the three main mathematical models published in literature investigating the mechanisms responsible for heat transfer variability between edge and central vials during freeze-drying. ${ }^{8,11,12}$ Two different approaches were used to describe the freeze-drying process: the dynamic state and the steady state. Gan et al. ${ }^{11}$ used the dynamic 2D model previously developed by Sheehan and Liapis ${ }^{13}$ to describe the heat transfer during freeze-drying in edge and central vials. The impact of the presence of a shielding band (rail) was also investigated. However, radiation from the wall and rail was considered to be the only mechanism responsible for the additional heat transfer received by edge vials. Furthermore, this model did not take into account the heat 
transfer contributions by radiation from the shelf to the vial bottom and contact conduction between the shelf and the vial bottom.

Recently, two mathematical models describing the heat transfer in edge vials assuming steady state were published. ${ }^{8,12}$

Pikal et al. ${ }^{8}$ used the theory described in Pikal $^{14}$ to evaluate the edge vial effect in terms of increment of vial heat transfer coefficient in edge vials compared to central vials $\Delta K_{V}^{E V}$. The relative contributions of three selected heat transfer mechanisms were evaluated, i.e., radiation from the wall and from the rail, contact conduction with the rail and the gas conduction between the rail and the vials. Although the equations of the model described by Pikal et al. ${ }^{8}$ can easily be solved using Excel, it requires the determination of a high number of parameters compared to other similar models (i.e., 18, Table 1). Furthermore, the use of a 1D model can be a limitation for the computation of complex heat fluxes (as, for example, radiation and gas conduction in the drying chamber). A step further in the understanding of the heat transfer mechanisms responsible of the edge vial effect was performed in Scutellà et al., ${ }^{12}$ who developed a 3D mechanistic mathematical model of heat transfer during sublimation. This model allows a detailed computation of the radiation heat fluxes between all the components of the considered system and of the conduction through the gas surrounding the vial in the drying chamber using a moderate number of model parameters (i.e., 5, Table 1).

In the present work, the model presented by Scutella et al. ${ }^{12}$ was further investigated to simulate three different vial loading configurations: vials partially shielded by the rail, vials totally shielded by the rail and vials totally exposed to the chamber walls. The performance of the models of Pikal et al. ${ }^{8}$ and Scutellà et al. ${ }^{12}$ was compared with experimental data published in literature. ${ }^{7}$ Then, the importance of the vial loading configuration on the heat transfer was assessed. Finally, the model was used to assess selected factors driving heat transfer inside a freeze-dryer unit, including the geometry and the thermal properties of the freeze-drying chamber.

\section{Mathematical Models}

\subsection{Geometry}

Scutellà et al. ${ }^{12}$ recently developed a $3 \mathrm{D}$ mathematical model of heat transfer during freeze-drying. The governing equations of the model were solved using the software COMSOL Multiphysics. The reference geometry of the model, presented in Figure 1A, included the drying chamber wall, bottom and top shelves, rail and five vials. The vials 
were made in borosilicate glass, filled with $1 \mathrm{~cm}$ of ice and arranged on the shelf in a hexagonal configuration. Vials located at the periphery of the shelf were alternatively in contact (vial C) and not in contact with the rail (vial E). The vial placed after the second row from the periphery of the shelf was considered to be a central vial (vial M). The rail in the reference configuration was designed to shield about $70 \%$ of the lateral side wall of the edge vials $\mathrm{C}$ and $\mathrm{E}$.

\subsection{Heat transfer phenomena}

The use of COMSOL Multiphysics allowed to precisely simulate the heat transfer during sublimation of pure ice. The contributions of the three main heat transfer mechanisms were taken into account: the contact conduction, the conduction through the gas and the radiation.

(a) Heat transfer by contact conduction between solid bodies. The contact conduction between the shelf and the vial bottom and the shelf and the rail was considered;

(b) Heat transfer by conduction through the gas in the drying chamber. The conduction through the low-pressure water vapour entrapped in the vial bottom concavity and surrounding the vial in the drying chamber was taken into account in the model. Due to the low pressure in the drying chamber (usually between $4-10 \mathrm{~Pa}$ ), the heat transfer takes place under free-molecular or Knudsen regime during sublimation near the solid walls. In the model of Scutellà et al., ${ }^{12}$ the Knudsen regime was simulated by designing a fictitious layer (named Knudsen layer) which covers all the solid bodies in contact with gas (i.e., vials, shelves, rail, wall, ice) and presents a pressure dependent heat transfer resistance;

(c) Radiation. The model developed by Scutellà et al. ${ }^{12}$ took into consideration the radiation heat transfer in the system, i.e., between ice surface, vials, shelf, rail and walls. The surface-to-surface radiation model proposed by COMSOL was used to evaluate the radiation heat fluxes by the hemicube method. This method automatically includes all the possible contributions to radiation heat transfer in the drying chamber and calculates the view factors for all the bodies present in the geometry, resulting in very accurate computation.

\subsection{Vial loading configurations investigated}

Using the mathematical model described by Scutellà et al., ${ }^{12}$ four different vial loading configurations were studied in this work: 
-Edge vials "partially shielded by the rail" (PS): This configuration was described by Scutellà et al. ${ }^{12}$ and is shown in Figure 1A. Vials are arranged on a tray surrounded by a metallic rail (known as "bottomless tray") and loaded on the freeze-dryer shelf. Then, the bottom of each tray is removed but the metallic rail remains. If the height of the rail is lower than the height of the vial, edge vials $\mathrm{C}$ and $\mathrm{E}$ are only partially exposed to the chamber wall. In the present case, a rail shielding about $70 \%$ of the vial height was considered (Figure 1A);

- Vials "partially exposed to the rail and located in the middle of the shelf" (PS'): Depending on the dimension of the shelf, several "bottomless trays" may be loaded on the same shelf of a freeze-dryer. In this case, one of the rail sides is not exposed to the wall, but to the rail of another tray, as shown in Figure 1B. In the present configuration, vials B and $\mathrm{D}$ represent vials partially exposed to the rail and placed alternatively in contact (vial B) and not in contact with the rail (vial D);

-Edge vials "totally shielded by the rail" (TS): In the "bottomless tray" configuration, if the height of the rail is equal to the height of the vials, only the rail is directly exposed to the chamber wall, as shown in Figure 1C;

-Edge vials "totally exposed to the wall" (TE): In manufacturing freeze-dryers, autoloading systems of vials are often used. Here, the vials are loaded directly on the shelves, without the aid of any tray or rail, as represented in Figure 1D. In this configuration, the lateral walls of the edge vials ( $\mathrm{C}$ and $\mathrm{E}$ ) are completely exposed to the heat transfer from the wall.

Relevant geometrical dimensions and thermal properties of the freeze-dryer considered in this study are reported in Table 2.

\subsection{Numerical solution}

COMSOL Multiphysics 5.2 (COMSOL, Inc, Burlington, USA) was employed to solve the mathematical model under steady-state condition, applying the finite-element method. General steps for the development of the model in COMSOL include the construction of the geometry, the definition of the model parameters and variables, the identification of the elements of the system and of the corresponding material properties, the assignment of the boundary conditions, and the generation of the proper mesh. In this work, numerical tests were based on non-structured meshing (tetrahedral elements).

\section{Results and discussion}




\subsection{Comparison of the simulated data obtained from Pikal et al. (2016) and Scutellà et al. (2017) with published experimental data}

The heat transfer model developed by Scutellà et al. ${ }^{12}$ was previously validated using experimental data in a wide range of operating conditions relevant for pharmaceutical freeze-drying: shelf temperatures between -40 and $0{ }^{\circ} \mathrm{C}$, and chamber pressures between 4 and $15 \mathrm{~Pa}$.

It is a common practice in literature to estimate the relative importance of the heat transfer mechanisms in edge and central vials by considering the vial heat transfer coefficient $K_{V} \cdot{ }^{8,9,15}$ However, this approach does not takes into account that the heat flow rates between the shelf and the vials and the additional heat flow rate received by edge vials are not due to the same temperature differences. Thus, in contrast to previous published works, it was decided to evaluate the heat transfer contributions not in terms of vial heat transfer coefficient $K_{V}$ but in terms of heat flow rates directly relevant to product temperature.

The performance of the model of Scutellà et al. ${ }^{12}$ in estimating the heat flow rate variability between edge and central vials was compared in this work with experimental data obtained from Rambhatla et al., ${ }^{7}$ who provide an extensive experimental study on the heat flow received by edge and central vials in a wide range of operating conditions.

Figure 2 compares the heat flow rate ratio between edge and central vials $Q_{\text {edge }} / Q_{\text {centre }}$ in a typical laboratory freeze-dryer estimated from (i) experimental data published by Rambhatla et al., ${ }^{7}$ (ii) simulated heat transfer data previously published by Pikal et al. ${ }^{8}$ and (iii) values predicted in this work using the model of Scutellà et al. ${ }^{12}$ The comparison was performed for low $\left(-25^{\circ} \mathrm{C}\right)$ and high $\left(-10{ }^{\circ} \mathrm{C}\right.$ and $\left.-15^{\circ} \mathrm{C}\right)$ shelf temperatures. Simulations using the model of Scutellà et al. ${ }^{12}$ were performed considering a similar vial loading configuration (i.e., vials completely exposed to the wall, TE configuration) and similar operating conditions than those used in the experimental study of Rambhatla et al. ${ }^{7}$ Conversely, the heat transfer data published by Pikal et al. ${ }^{8}$ referred to similar operating conditions but to a different vial loading configuration (i.e., vials partially shielded by the rail, PS configuration) than Rambhatla et al. ${ }^{7}$ The PS vial loading configuration simulated in the work of Pikal et al. ${ }^{8}$ is known to present a lower heat transfer variability between edge and central vials respect the TE configuration. ${ }^{7,11}$

At high shelf temperature, both models of Scutella et al. ${ }^{12}$ and of Pikal et al. ${ }^{8}$ satisfactorily agreed with the average experimental heat flow rate ratio $Q_{\text {edge }} / Q_{\text {centre }}$ calculated from 
the sublimation rate reported in Rambhatla et al., ${ }^{7}$ with a maximum deviation of $4 \%$. In contrast, at low shelf temperature, the average experimental value $Q_{\text {edge }} / Q_{\text {centre }}$ calculated from the sublimation rate reported in Rambhatla et al. ${ }^{7}$ appeared to be well in agreement with the values predicted by the model of Scutellà et al. ${ }^{12}$ (deviation of about 2 $\%$ ), whereas it was overestimated by about $30 \%$ by the model of Pikal et al. ${ }^{8}$

The overestimation of the heat transfer ratio between edge and central vials obtained from the model of Pikal et al. ${ }^{8}$ at low shelf temperature may be due to an overestimation of the radiation heat fluxes received by edge vials. Pikal et al. ${ }^{8}$ estimated the radiative heat fluxes by using the Stefan-Boltzmann equation and evaluated the visualization factors between walls, rail and vials using a catalog from the web (http://www.thermalradiation.net). This approach may not be accurate enough to quantify radiative heat transfer contributions in a system of such complex geometry as the drying chamber. This issue was overcome in the $3 \mathrm{D}$ model of Scutellà et al. ${ }^{12}$ by estimating the radiation heat fluxes in the drying chamber using the hemicube method.

\subsection{Effect of the vial loading configuration on the edge vial effect}

Figure 3 presents the relative importance of the heat flow rate received by edge vials compared to the heat flow rate received by central vials (vial M) (expressed as the heat flow rate ratio $\left.Q_{\text {edge }} / Q_{\text {centre }}\right)$. Four different vial loading configurations were investigated: edge vials partially shielded by the rail (PS), vials partially exposed to the rail and located in the middle of the shelf (PS'), edge vials totally shielded by the rail (TS) and vials totally exposed to the wall (TE). The simulations were run at chamber pressure of $4 \mathrm{~Pa}$ and two shelf temperatures, $0{ }^{\circ} \mathrm{C}$ and $-40{ }^{\circ} \mathrm{C}$.

Regardless of the loading configuration, vials in contact with the rail (vial $\mathrm{C}$ or $\mathrm{B}$ ) exhibited a heat flow rate at least $30 \%$ higher than central vials M. In contrast, the additional heat flow rate received by vials not in contact with the rail (vial E or D) compared to central vial $\mathrm{M}$ was lower than $10 \%$.

Furthermore, when considering a shelf temperature of $0{ }^{\circ} \mathrm{C}$ (Figure $3 \mathrm{~A}$ ), the vial loading configuration did not show a significant impact on the heat transfer ratio between edge and central vials (about $35 \%$ ) for the PS, TS and PS' configuration, slightly higher (about $40 \%$ ) for the TE configuration. The influence of the loading configuration was more visible at low shelf temperatures $\left(-40^{\circ} \mathrm{C}\right.$, Figure $\left.3 \mathrm{~B}\right)$. The use of the rail appeared to significantly decrease the heat transfer ratio between edge and central vials of about 15 
\%. This result is agreement with the experimental data published by Rambhatla et al., ${ }^{7}$ from which was estimated an increase of the $Q_{\text {edge }} / Q_{\text {centre }}$ of about $10 \%$ between configurations with and without stainless steel rail considering a shelf temperature of -25 ${ }^{\circ} \mathrm{C}$.

However, the use of a metallic rail shielding $70 \%$ or $100 \%$ the vial lateral wall (as in PS and TS configurations) only leads to a $5 \%$ decrease of the heat transfer ratio between edge vial $\mathrm{C}$ in contact with the rail and central vial $\mathrm{M}$. Similar results were found from Pikal et al., ${ }^{8}$ who report a non-significant increase of the edge vial heat transfer coefficient $K_{V}^{E V}$ when rails shielding about $30 \%$ or $80 \%$ of the side wall of the vial were used.

Furthermore, when decreasing shelf temperature, the value of the heat flow rate ratio $Q_{\text {edge }} / Q_{\text {centre }}$ increased in vial C for vial loading configurations including wall (TE, PS and TS), which was mainly ascribed to an increased contribution of heat transfer by radiation (e.g., from $10 \%$ at $0{ }^{\circ} \mathrm{C}$ to $20 \%$ at $-40{ }^{\circ} \mathrm{C}$ in TE configuration).

In order to better understand the effect of both vial position and loading configuration, the individual contributions to heat transfer of the shelves, the rail and the wall were evaluated.

Figure 4 shows the relative importance of heat flow contributions of (i) heat transfer from the bottom shelf to the vial, including contact conduction, radiation, and gas conduction, (ii) conduction through the gas surrounding the sides and top of the vials, (iii) radiation from the rail and (iv) radiation from the top shelf, the chamber wall and other vial walls, in the three different configurations (TE, PS, TS).

As expected, the heat flow rates from the bottom shelf played a major role on the total heat transfer and its relative importance decreased when distance between the vial and the rail decreased (from vial $\mathrm{M}$ to vial $\mathrm{C}$ ). Conversely, the contribution of gas conduction increased when getting closer to the rail and was higher than radiation in all configurations. This finding confirmed the results of Scutellà et al. ${ }^{15}$ that ascribed the additional heat flow rate received by edge vials mainly to the conduction through the water vapour contained in the drying chamber.

Furthermore, when considering the edge vials $\mathrm{C}$ and $\mathrm{E}$, the use of shielding rails in the PS and TS configurations led to a lower contribution of radiation from the wall (represented in black in Figure 4) with respect to the TE configuration. The rail contributed itself to the total heat flow rates by radiation (represented in white in Figure 4), which appeared to be 
significant especially for the edge vial C. However, total contribution of heat transfer by radiation including the rail, the wall, the shelves and the vial walls received by edge vials was significantly reduced when a shielding rail was used (PS and TS configuration compared to TE configuration).

When considering the central vial $\mathrm{M}$, the use of the rail slightly decreased the importance of the radiation heat flow from the top shelf, the walls and the vial walls. This effect was probably due to the proximity of the simulated central vial $M$ (located in the third row of the array) to the rail and the edge of the shelf. In real systems, heat transfer in central vials located far from the rail should be almost unaffected by the rail.

\subsection{Effect of the rail thermal conductivity and emissivity on the edge vial effect}

As shown in Figure 4, the presence of the rail in the vial loading configuration allows to shield the edge vials from the radiation of the chamber wall, but it still has a significant impact on the edge vial effect through radiation and gas conduction. Thus, the understanding of the effect of the thermal characteristics (i.e., emissivity and thermal conductivity) of the rail on the heat transfer in edge vials can guide the choice of the rail material and thus the design of the freeze-drying cycle.

Firstly, the impact of the rail emissivity on the heat transfer in edge vials was tested at a chamber pressure of $4 \mathrm{~Pa}$ in the TS configuration (totally shielded by the rail) by considering two shelf temperatures, $0{ }^{\circ} \mathrm{C}$ and $-40{ }^{\circ} \mathrm{C}$ and a range of rail emissivity between 0.05 and 1. The variation of the emissivity of the rail did not modify the additional heat flow rates received by either the vial $\mathrm{C}$ or $\mathrm{E}$ (data not shown). This result is supported by the limited contribution of the radiation heat flow rates from the rail received by the edge vials (between 2 and $10 \%$, Figure 4).

Then, the relative importance of the heat flow rate in vial $\mathrm{C}$ and $\mathrm{E}$ compared to the one received by the central vial $\mathrm{M}$ in the TS configuration was evaluated for different values of rail thermal conductivity (between 0.01 and $16.5 \mathrm{~W} \mathrm{~m}^{-1} \mathrm{~K}^{-1}$ ). The thermal conductivity has an impact on the rail surface temperature (named $T_{r}$ ), which in turn will influence the conduction through the gas contained in the gap between the rail and the vial and the radiation. The results are presented in Figure 5. A chamber pressure of $4 \mathrm{~Pa}$ and two shelf temperatures, $0{ }^{\circ} \mathrm{C}$ and $-40{ }^{\circ} \mathrm{C}$, were tested. The use of a material with an increasing thermal conductivity from $0.01 \mathrm{~W} \mathrm{~m}^{-1} \mathrm{~K}^{-1}$ to $16.5 \mathrm{~W} \mathrm{~m}^{-1} \mathrm{~K}^{-1}$ resulted in increasing the rail surface temperature $T_{r}$ by a maximum of $3{ }^{\circ} \mathrm{C}$. The increased rail temperature led to an increase of the heat flow rates ratio between edge vial $\mathrm{C}$ and central vial $\mathrm{M}$ of $4 \%$ at $0{ }^{\circ} \mathrm{C}$ 
and of $3 \%$ at $-40{ }^{\circ} \mathrm{C}$. The use of rail with thermal conductivities higher than $1 \mathrm{~W} \mathrm{~m}^{-1} \mathrm{~K}^{-1}$ did not result in a further increase of the heat flow rate ratio between edge and central vials because the rail temperature became almost uniform and the main heat transfer resistance was located at the rail-shelf contact. The effect of the rail thermal conductivity on the heat transfer was thus limited but not completely negligible for vial C. In contrast, the edge vial $\mathrm{E}$ was not affected by the thermal conductivity of the rail in the whole range tested, regardless of the shelf temperature considered. The impact of the rail conductivity on the edge vial effect calculated in the present work appeared to be in agreement to literature results. As an example, the heat flow ratio between edge and central vial $Q_{\text {edge }} / Q_{\text {centre }}$ calculated using experimental data published by Rambhatla et al., ${ }^{7}$ showed an increase of about $5 \%$ when the conductivity of the rail increased from $0.03 \mathrm{~W} \mathrm{~m}^{-1} \mathrm{~K}^{-}$ ${ }^{1}$ (styrofoam rail) to $16.5 \mathrm{~W} \mathrm{~m}^{-1} \mathrm{~K}^{-1}$ (stainless steel rail).

The limited effect of the rail thermal conductivity can be explained from the visualization of the heat fluxes in the system. Figure 6 presents a view of the drying chamber, in which is shown the gas contained in the gap between the rail, the bottom shelf and the edge vials (only vial E visible). The temperature is represented by the colour scale, whereas heat fluxes are represented by arrows, whose dimension is proportional to the flux magnitude on a logarithmic scale. A rail thermal conductivity of $16.5 \mathrm{~W} \mathrm{~m}^{-1} \mathrm{~K}^{-1}$ and an emissivity of 0.13 at $4 \mathrm{~Pa}$ and $0{ }^{\circ} \mathrm{C}$ were used in this simulation. Heat fluxes directed to the lateral side of the vials were mainly coming from the bottom shelf area between the vials and the rail (upward arrows) through gas conduction, as evidenced by the white rectangle and the inset. Thus, the rail's contribution to the lateral flux by gas conduction received by edge vials was small and modifications of the rail conductivity had only a limited impact on the lateral heat flux.

\subsection{Effect of the equipment dimensions and emissivity on the heat transfer in the drying chamber}

During scale-up, the cycle is transferred from pilot to commercial freeze-dryers which can have different dimensions (e.g., distances between the shelf and the wall and between shelves). Furthermore, measurements in several freeze-dryers of different scales have shown that the wall and shelf emissivity can vary in a range of 0.04 to 0.4 . These features may modify the heat flow rates received by the vials respectively by gas conduction and radiation. 
Figure 7 shows the heat flow rates received by vials $\mathrm{C}, \mathrm{E}$ and $\mathrm{M}$ at $4 \mathrm{~Pa}$ and $0{ }^{\circ} \mathrm{C}$ in the TE configuration (totally exposed) considering different wall emissivities and different distances between the shelves and the wall. The dotted vertical lines represent the values for the freeze-dryer considered for the simulation (Table 2). A variation of the wall emissivity between 0.01 and 0.5 resulted in an increase of the heat flow received by vials $\mathrm{C}, \mathrm{E}$ and $\mathrm{M}$ of about 2, 4 and $5 \%$, respectively (Figure 7A). The heat flow rates in edge vials $\mathrm{C}$ decreased by about $5 \%$ when the distance between the shelves and the wall increased from $3.5 \mathrm{~cm}$ to $20 \mathrm{~cm}$ (Figure 7B), whereas vial $\mathrm{E}$ and $\mathrm{M}$ were not significantly affected. The variations of heat flow rate due to the wall emissivity and the distance between wall and shelves appears to have a minor impact on heat transfer, within measurement error and modelling uncertainty.

Figure 8 presents the heat flows received by the vials $\mathrm{C}, \mathrm{E}$ and $\mathrm{M}$ at a pressure of $4 \mathrm{~Pa}$ and a shelf temperature of $0{ }^{\circ} \mathrm{C}$ in the TE configuration considering different shelf emissivities and different distances between the top and bottom shelves. An increase of the shelf emissivity from 0.01 to 0.5 caused an increase of the heat flow of about $5 \%$ in vial C, $13 \%$ in vial $\mathrm{E}$ and $15 \%$ in vial M (Figure $8 \mathrm{~A}$ ). The impact of the shelf emissivity on the heat flow rates appeared to be more important than the wall emissivity. This result pointed out that a variation of the shelf emissivity between one freeze-dryer and another cannot be neglected, and a precise thermal characterization (i.e., emissivity measurement) of the equipment may be necessary before performing scale-up. Furthermore, the heat flow decreased by about $5 \%$ in all considered vials when the distance between the shelves increased from $3.5 \mathrm{~cm}$ to $10 \mathrm{~cm}$ (Figure 8B). Further increase of the distance (up to $20 \mathrm{~cm}$ ) did not have any significant impact on the heat transfer. These results can be explained by a decrease of the gas conduction flow and of the view factor relevant to radiation at distances between the shelves higher than about $10 \mathrm{~cm}$. To our knowledge, there are no published works that studied the impact of the equipment dimensions and emissivity of the drying chamber on the heat transfer in edge and central vials during sublimation.

\section{Conclusions}

In the present work, the 3D heat transfer model previously developed in COMSOL by Scutellà et al., ${ }^{12}$ was used to predict the impact of several factors on the variability of heat transfer between edge and central vials, such as the vial loading configurations, the thermal properties of the rail, the walls and the shelves and some characteristic 
dimensions of the drying chamber (i.e., distance between the shelf and the wall and distance between shelves). In addition to previously performed experimental validation, ${ }^{12}$ the considered model accurately predicted the heat flow rate ratio between edge and central vials estimated from experimental data of Rambhatla et al. ${ }^{7}$ at both high and low shelf temperatures.

The use of the model revealed that the loading configuration plays a significant role in the heat transfer variability between edge and central vials. The use of a rail shielding more than $70 \%$ of the lateral side of vials located at the periphery of the shelf was found to significantly reduce the edge vial effect. However, the rail itself contributes to the heat transfer and its contribution has to be considered when it is present in the middle of a shelf, i.e., when several trays are used on a same shelf.

Furthermore, among the different thermal properties of the drying chamber components (rail, walls, shelves), the emissivity of shelf was found to significantly influence the heat flow received by both edge and central vials. Thus, a precise measurement of shelf emissivity is recommended to predict the heat transfer modification between equipment presenting different finish of the shelves. Among the explored geometric dimensions of the freeze-dryer, a distance between shelves less than about $5 \mathrm{~cm}$ slightly increased the heat transfer while the distance between shelves and walls had a negligible effect in the considered range.

The developed model revealed to be a powerful tool, to be used during the cycle design and scale-up process to predict the heat transfer variability between edge and central vials, but also between different freeze-dryers. 


\section{References}

1. Hansen LJJ, Daoussi R, Vervaet C, Remon JP, De Beer TRM. Freeze-drying of live virus vaccines: A review. Vaccine 2015;33(42):5507-5519.

2. Pikal MJ. Freeze-Drying of Proteins. In: Cleland JL, Langer R, eds. Formulation and Delivery of Proteins and Peptides, ACS Symposium Series; 1994:120-133.

3. Patel SM, Jameel F, Pikal MJ. The effect of dryer load on freeze drying process design. J Pharm Sci 2010;99(10):4363-4379.

4. Tchessalov S, Dixon D, Warne NW. Principles of lyophilization cycle scale-up. Am Pharm Rev 2007;10(2):88-92.

5. Kramer T, Kremer DM, Pikal MJ, Petre WJ, Shalaev EY, Gatlin LA. A procedure to optimize scale-up for the primary drying phase of lyophilization. J Pharm Sci 2009; 98(1):307-318.

6. Fissore D, Barresi AA. Scale-up and Process Transfer of Freeze-Drying Recipes. Drying Technol 2011;29(14):1673-1684.

7. Rambhatla S, Pikal MJ. Heat and mass transfer scale-up issues during freeze-drying, I: atypical radiation and the edge vial effect. AAPS PharmSciTech 2003;4(2):E14.

8. Pikal MJ, Bogner R, Mudhivarthi V, Sharma P, Sane P. Freeze-Drying Process Development and Scale-Up: Scale-Up of Edge Vial Versus Center Vial Heat Transfer Coefficients, Kv. J Pharm Sci 2016;105(11):3333-3343.

9. Pisano R, Fissore D, Barresi AA, Brayard P, Chouvenc P, Woinet B. Quality by design: optimization of a freeze-drying cycle via design space in case of heterogeneous drying behavior and influence of the freezing protocol. Pharm Dev Technol 2013;18(1):280295.

10. Tang X, Nail SL, Pikal MJ. Evaluation of manometric temperature measurement, a process analytical technology tool for freeze-drying: Part I, product temperature measurement. AAPS PharmSciTech 2006;7(1):E95-E103.

11. Gan KH, Bruttini R, Crosser OK, Liapis AI. Freeze-drying of pharmaceuticals in vials on trays: effects of drying chamber wall temperature and tray side on lyophilization performance. Int J Heat Mass Transfer 2005;48(9):1675-1687.

12. Scutellà B, Plana-Fattori A, Passot S, Bourlès E, Fonseca F, Flick D, Tréléa IC. 3D mathematical modelling to understand atypical heat transfer observed in vial freeze-drying. Appl Therm Eng 2017;126:226-236.

13. Sheehan P, Liapis AI. Modeling of the primary and secondary drying stages of the freeze drying of pharmaceutical products in vials: numerical results obtained from the solution of a dynamic and spatially multi-dimensional lyophilization model for different operational policies. Biotechnol Bioeng 1998;60(6):712-728.

14. Pikal MJ. Use of Laboratory Data in Freeze Drying Process Design: Heat and Mass Transfer Coefficients and the Computer Simulation of Freeze Drying. PDA Journal of Pharm Sci Technol 1985;39(3):115-139.

15. Hibler S, Wagner C, Gieseler H. Vial freeze-drying, part 1: new insights into heat transfer characteristics of tubing and molded vials. J Pharm Sci 2012;101(3):1189-1201.

16. Scutella B, Passot S, Bourles E, Fonseca F, Trelea IC. How Vial Geometry Variability Influences Heat Transfer and Product Temperature During Freeze-Drying. J Pharm Sci 2017;106(3):770-778. 


\section{ACKNOWLEDGMENTS}

The authors would like to thank Yves Mayeresse and Benoit Moreau (GSK Vaccines) for reviewing this work, Vincent Ronsse (technician) and Alain Philippart (operator) (GSK Vaccines) for their help in the data acquisition and Victor Rousseau and Gwenael Davaud (AgroParisTech students) for their help in developing the model.

\section{CONFLICT OF INTEREST}

Erwan Bourlès is an employee of the GSK group of companies. Bernadette Scutellà participated in a postgraduate $\mathrm{PhD}$ program at GSK Vaccines. Stephanie Passot, Fernanda Fonseca, Artemio Plana-Fattori, Denis Flick and Ioan Cristian Trelea report no financial conflicts of interest.

\section{FUNDING}

This work was funded by GlaxoSmithKline Biologicals S.A., under a Cooperative Research and Development Agreement with INRA (Institut National de la Recherche Agronomique) via the intermediary of the UMR (Unité Mixte de Recherche) GMPA (Génie et Microbiologie des Procédés Alimentaires) at the INRA Versailles-Grignon research centre.

\section{AUTHORS CONTRIBUTIONS}

All authors were involved in the conception of the model and design of the study. Bernadette Scutellà, Erwan Bourlès, acquired the data. Bernadette Scutellà, Stephanie Passot, Erwan Bourlès, Fernanda Fonseca and Ioan Cristian Trelea analyzed and interpreted the experimental results. Bernadette Scutellà, Artemio Plana-Fattori, Denis Flick, and Ioan Cristian Trelea were involved in the model development. All authors were involved in drafting the manuscript or revising it critically for important intellectual content. All authors had full access to the data and approved the manuscript before it was submitted by the corresponding author. 
Table 1: Summary of the main mathematical models published in literature describing the edge vial effect during freeze-drying process

\begin{tabular}{|c|c|c|c|}
\hline & Gan et $a l .{ }^{11}$ & Pikal et $a l .{ }^{8}$ & Scutellà et $a l^{12}$ \\
\hline $\begin{array}{c}\text { Scope of the } \\
\text { work }\end{array}$ & $\begin{array}{l}\text { Assess the role played } \\
\text { by the presence of the } \\
\text { trays on the drying times } \\
\text { and on the distribution } \\
\text { of bound water } \\
\text { concentration } \\
\text { (based on the model of } \\
\text { Sheehan and Liapis }{ }^{13} \text { ) }\end{array}$ & $\begin{array}{l}\text { Scale-up of the edge vial } \\
\text { effect } \\
\text { (based on the model of }^{\text {Pikal }^{14} \text { ) }}\end{array}$ & $\begin{array}{l}\text { Original mathematical } \\
\text { model to predict the } \\
\text { edge vial effect and } \\
\text { understand the heat } \\
\text { transfer mechanisms } \\
\text { responsible of it }\end{array}$ \\
\hline State & Dynamic state & Steady state & Steady state \\
\hline $\begin{array}{c}\text { Model } \\
\text { dimensions }\end{array}$ & $2 \mathrm{D}$ & $1 \mathrm{D}$ & $3 \mathrm{D}$ \\
\hline $\begin{array}{l}\text { Number of } \\
\text { model } \\
\text { parameters* }\end{array}$ & 6 & 18 & 5 \\
\hline $\begin{array}{l}\text { Heat transfer } \\
\text { mechanisms } \\
\text { between the } \\
\text { shelf and the } \\
\text { vial }\end{array}$ & Gas conduction & $\begin{array}{l}\text { Contact conduction, } \\
\text { radiation and gas } \\
\text { conduction }\end{array}$ & $\begin{array}{l}\text { Contact conduction, } \\
\text { radiation and gas } \\
\text { conduction }\end{array}$ \\
\hline $\begin{array}{l}\text { Heat transfer } \\
\text { mechanisms } \\
\text { accounted for } \\
\text { the edge vial } \\
\text { effect }\end{array}$ & $\begin{array}{l}\text { Radiation from the wall } \\
\text { and the rail }\end{array}$ & $\begin{array}{l}\text { Radiation from the wall } \\
\text { and the rail } \\
\text { Gas conduction between } \\
\text { the vial and the rail }\end{array}$ & $\begin{array}{l}\text { Radiation from the wall } \\
\text { and the rail } \\
\text { Gas conduction in the } \\
\text { drying chamber }\end{array}$ \\
\hline $\begin{array}{l}\text { Radiation } \\
\text { model }\end{array}$ & $\begin{array}{l}\text { Stefan-Bolzmann } \\
\text { equation }\end{array}$ & $\begin{array}{l}\text { Stefan-Bolzmann } \\
\text { equation }\end{array}$ & $\begin{array}{l}\text { Surface to surface model } \\
\text { proposed by COMSOL } \\
\text { Multiphysics and based } \\
\text { on the hemicube method }\end{array}$ \\
\hline
\end{tabular}

*considering a fixed vial and drying chamber geometry (geometrical parameters are not included) 
Table 2: Thermal properties and relevant dimensions of the freeze-dryer used

\begin{tabular}{|c|c|}
\hline Characteristic & Value \\
\hline Number of shelves & 7 \\
\hline Area of each shelf & $0.27 \mathrm{~m}^{2}$ \\
\hline Distance between shelves & $0.06 \mathrm{~m}$ \\
\hline $\begin{array}{l}\text { Distance between } \\
\text { the wall and the shelf }\end{array}$ & $0.11 \mathrm{~m}$ \\
\hline Thermal conductivity of the rail & $16.5 \mathrm{~W} \mathrm{~m}^{-1} \mathrm{~K}^{-1}$ \\
\hline Emissivity of the walls and the rail & $0.13^{a}$ \\
\hline Emissivity of the shelf & $0.18^{b}$ \\
\hline Emissivity of the vial glass & $0.78^{b}$ \\
\hline
\end{tabular}




\section{Figure Captions}

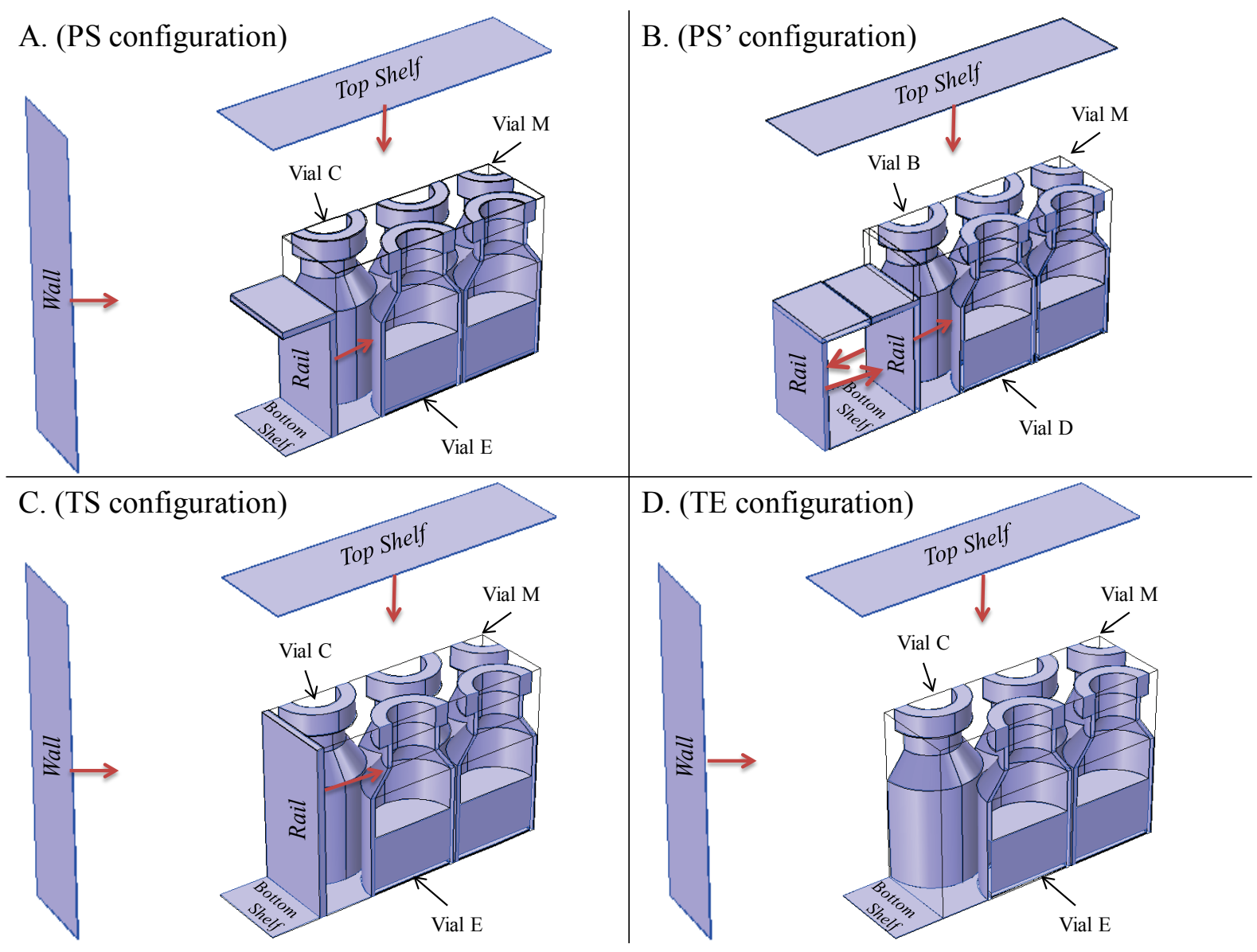

Figure 1: Loading configurations studied in this work and typically used in freeze-drying process: (A) edge vials "partially shielded by the rail", named PS; (B) vials "partially exposed to the rail and located in the middle of the shelf", named PS'; (C) edge vials "totally shielded by the rail", named TS; (D) edge vials "totally exposed to the wall", named TE. In function of their positions, the vials are classified as edge vial $\mathrm{C}$ and $\mathrm{E}$ or $\mathrm{B}$ and $\mathrm{D}$ and central vial $\mathrm{M}$. 


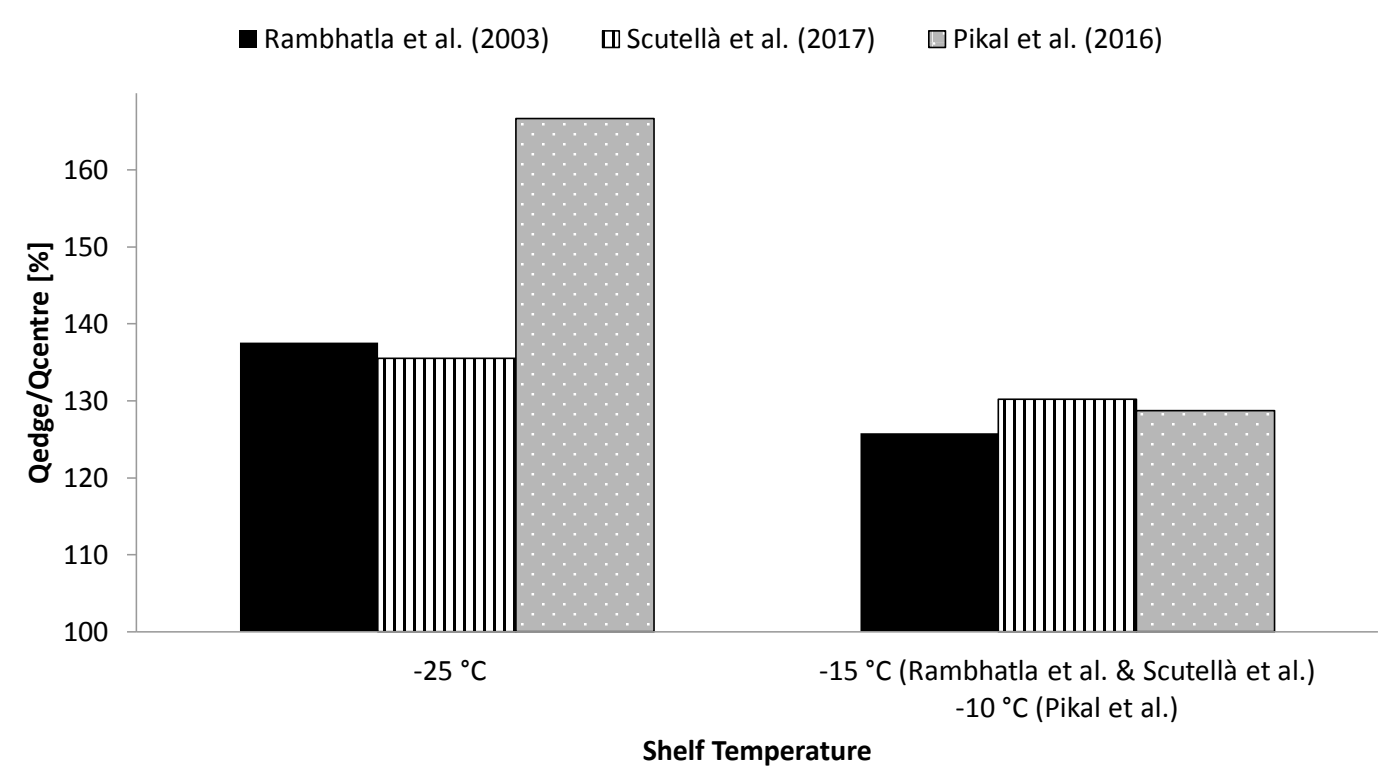

Figure 2: Comparison of heat flow rate ratio between edge and central vials $Q_{\text {edge }} /$ $Q_{\text {centre }}$ assessed from experimental data published by Rambhatla et al. ${ }^{7}$ and predicted by the mathematical models of Pikal et al. ${ }^{8}$ and Scutellà et al. ${ }^{12}$ High shelf temperature corresponds to $-15{ }^{\circ} \mathrm{C}$ in the work of Rambhatla et al. ${ }^{7}$ and Scutellà et al. ${ }^{12}$ and to $-10{ }^{\circ} \mathrm{C}$ in Pikal et al., ${ }^{8}$ whereas low shelf temperature to $-25{ }^{\circ} \mathrm{C}$ in all cases. Other relevant process conditions: (i) Rambhatla et al. ${ }^{7}$ and Scutellà et al.: ${ }^{12}$ chamber pressure of $20 \mathrm{~Pa}$, vial and door emissivity respectively equal to 0.9 and 0.95 , TE configuration; (ii) Pikal et al.. ${ }^{8}$ chamber pressure of about $10 \mathrm{~Pa}$, vial and wall emissivity respectively equal to 0.95 and 0.65 , PS configuration. 


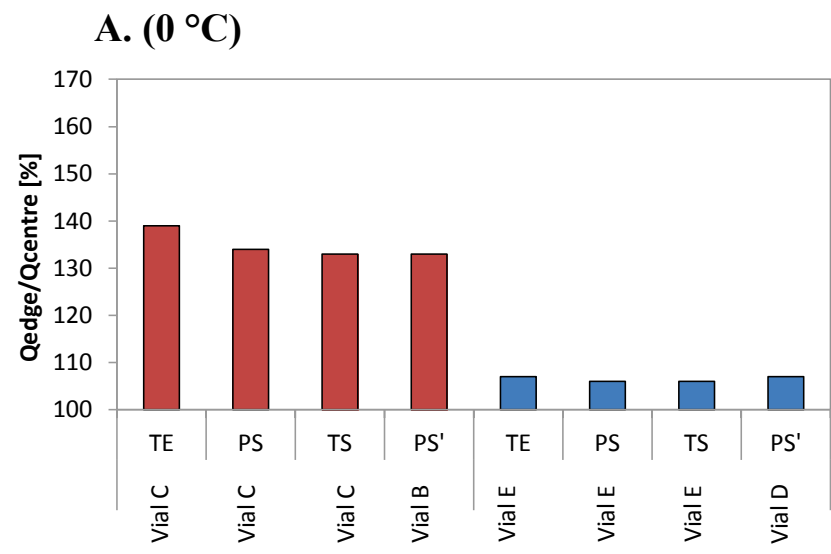

B. $\left(-40^{\circ} \mathrm{C}\right)$

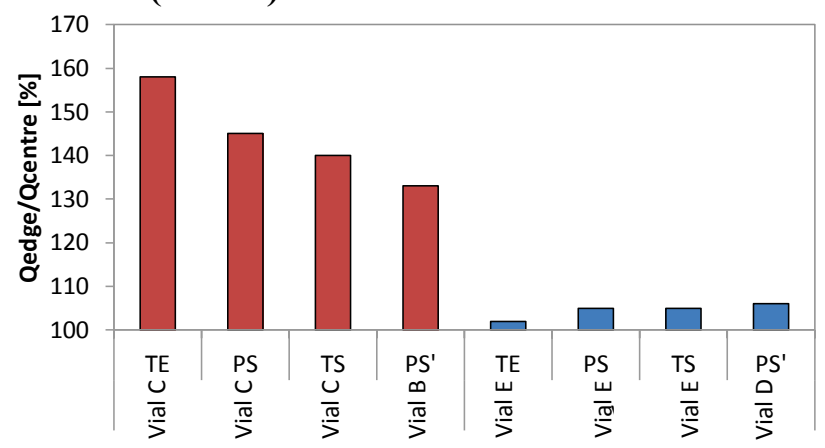

Figure 3: Heat flow rates received by edge vials $\mathrm{C}$ and $\mathrm{E}$ or $\mathrm{B}$ and $\mathrm{D}$ ( $\left.\mathrm{Q}_{\text {edge}}\right)$ relative to the heat flow rate received by central vial $\mathrm{M}\left(\mathrm{Q}_{\text {centre }}\right)$, evaluated for the four different loading configurations studied (TE, PS, TS, PS'), for a chamber pressure of $4 \mathrm{~Pa}$ and for two shelf temperatures: (A) $0{ }^{\circ} \mathrm{C}$ and (B) $-40{ }^{\circ} \mathrm{C}$. Significance of the abbreviations of vials C, E, B, D and $\mathrm{M}$ is reported in Figure 1. TE, PS, TS and PS' configurations are described in Figure 1. 


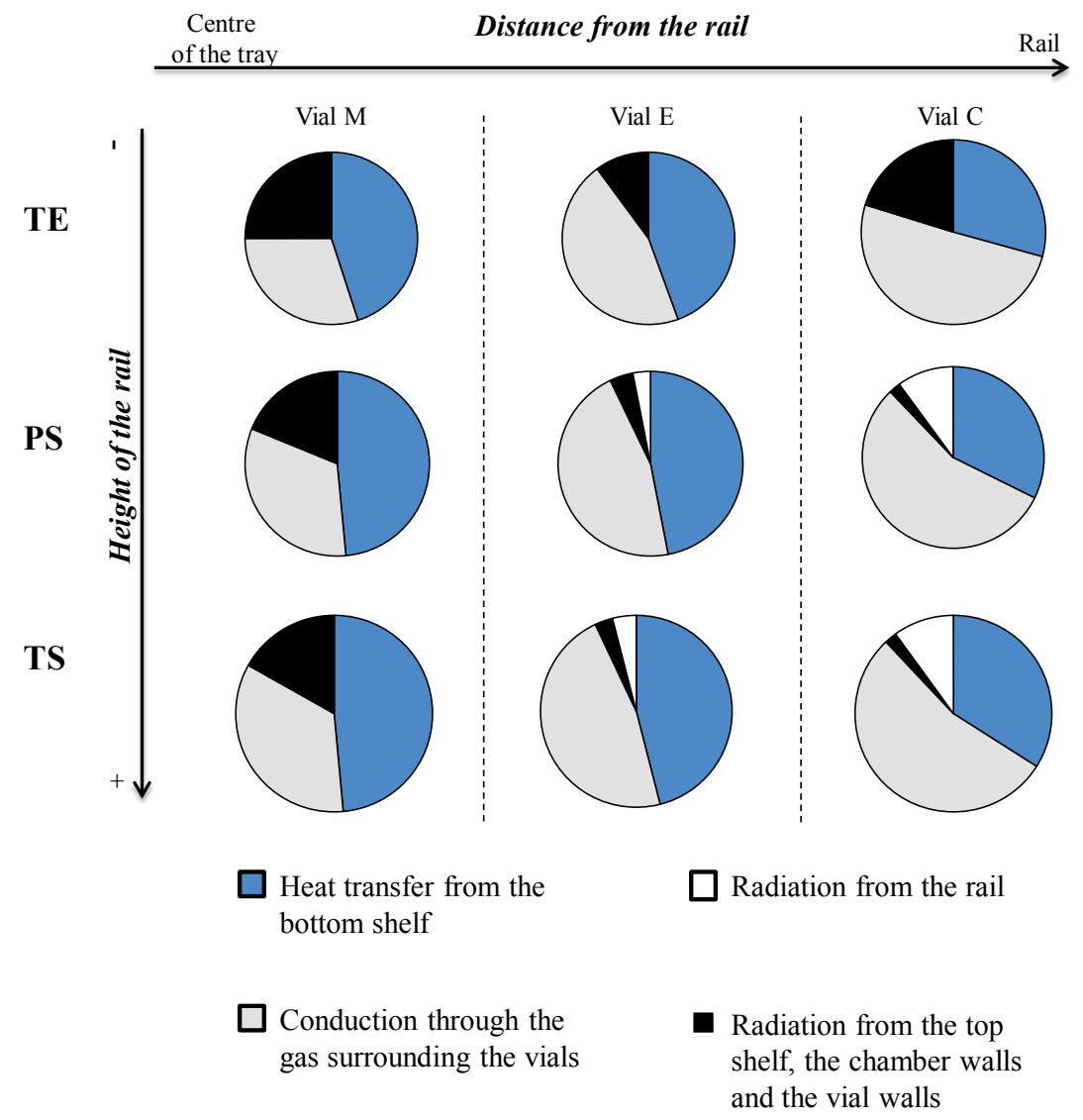

Figure 4: Relative importance of various heat transfer mechanisms with respect to the total heat flow rate in three different loading configurations (TE, PS, TS) at a chamber pressure of $4 \mathrm{~Pa}$ and a shelf temperature of $-40{ }^{\circ} \mathrm{C}$. Significance of the abbreviations of vials C, E, B, D and $\mathrm{M}$ is reported in Figure 1. TE, PS and TS configurations are described in Figure 1. 

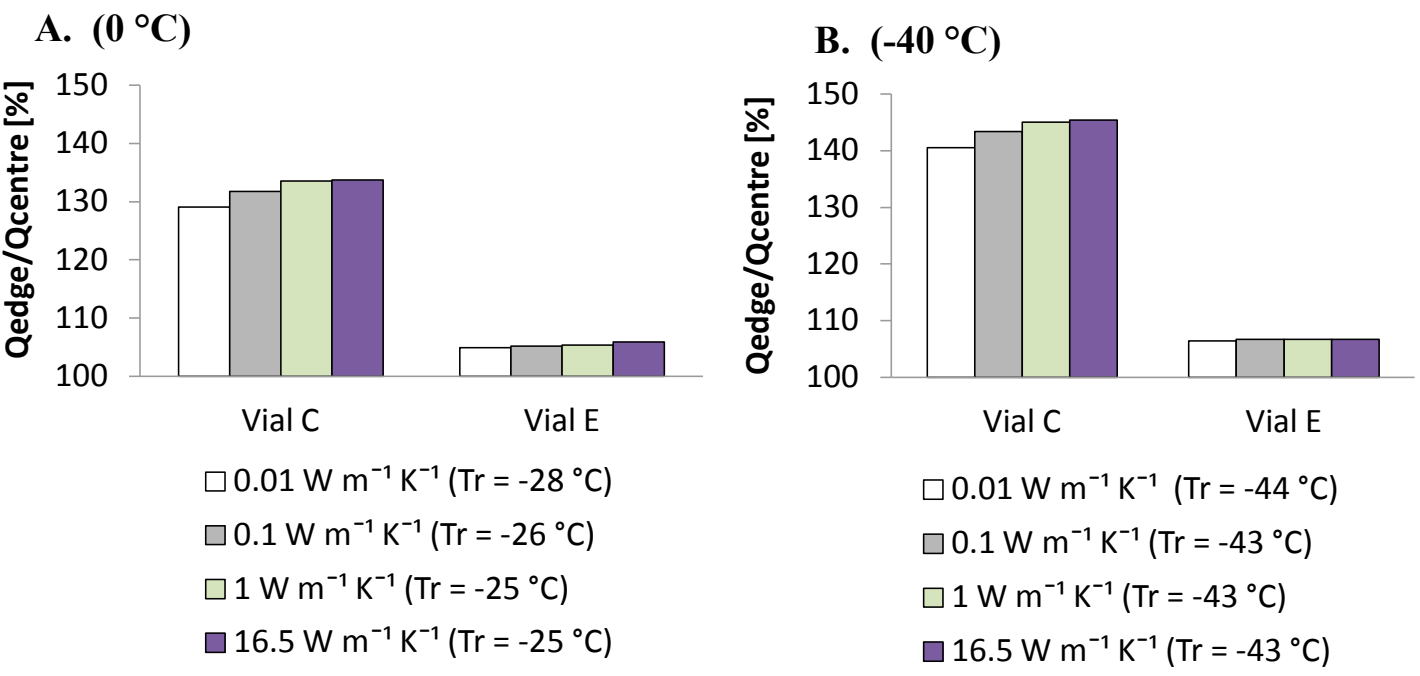

Figure 5: Heat flow rate received by edge vials $C$ or $E\left(Q_{\text {edge }}\right)$ relative to the heat flow rate received by central vial $\mathrm{M}\left(\mathrm{Q}_{\text {centre}}\right)$, evaluated in the $\mathrm{TS}$ configuration at $(\mathrm{A}) 0^{\circ} \mathrm{C}$ and $4 \mathrm{~Pa}$ and (B) $-40{ }^{\circ} \mathrm{C}$ and $4 \mathrm{~Pa}$ considering four different rail thermal conductivities. $T_{r}$ represents the temperature of the rail evaluated for each value of thermal conductivity tested. TS: edge vials totally shielded by the rail. Significance of the abbreviations of vials $C, E$ and $M$ is reported in Figure 1. 


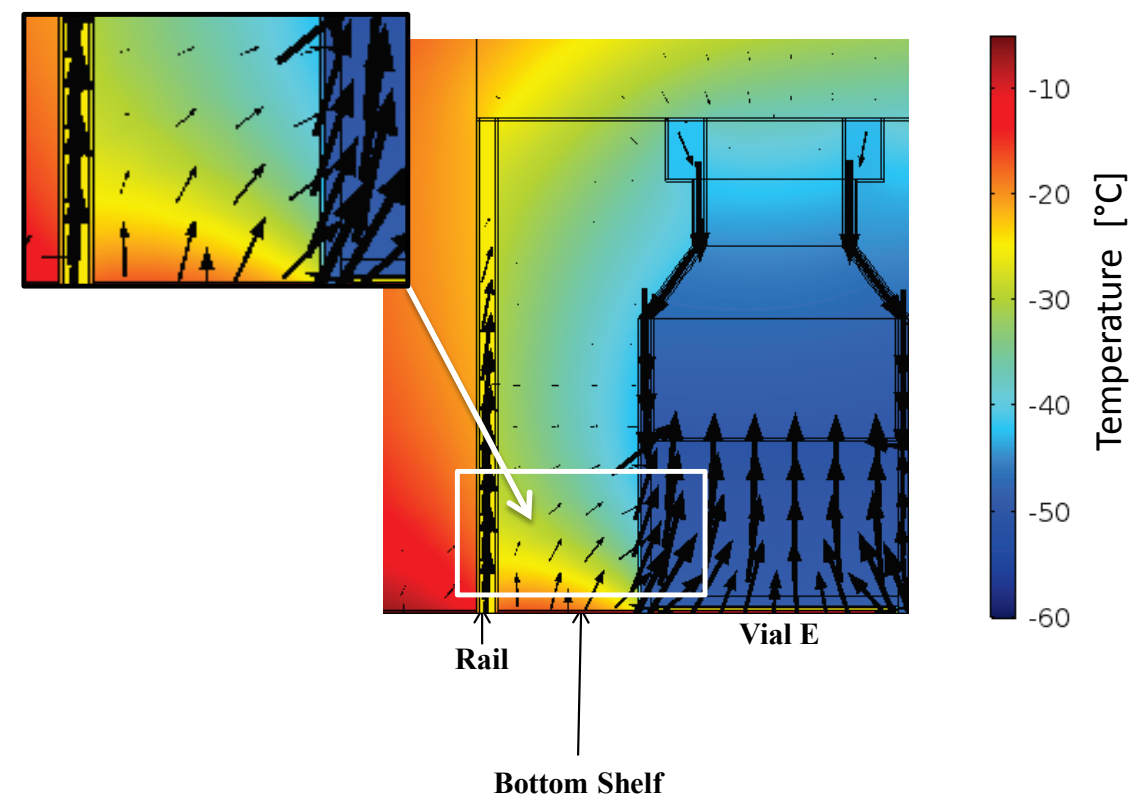

Figure 6: Temperature profiles and heat fluxes in the TS configuration at a shelf temperature of $0{ }^{\circ} \mathrm{C}$ and a chamber pressure of $4 \mathrm{~Pa}$ for a rail thermal conductivity of $16.5 \mathrm{~W} \mathrm{~m}^{-1} \mathrm{~K}^{-1}$ and emissivity of 0.13 . The view shows the gap between the rail, the bottom shelf and the edge vials (only vial $\mathrm{E}$ visible). Arrow dimension indicates heat flux magnitude on a logarithmic scale. The white rectangle and the inset to the figure indicates the lateral heat fluxes from bottom shelf to edge vials. TS: edge vials totally shielded by the rail. Vial E: edge vial not in contact with the rail. 


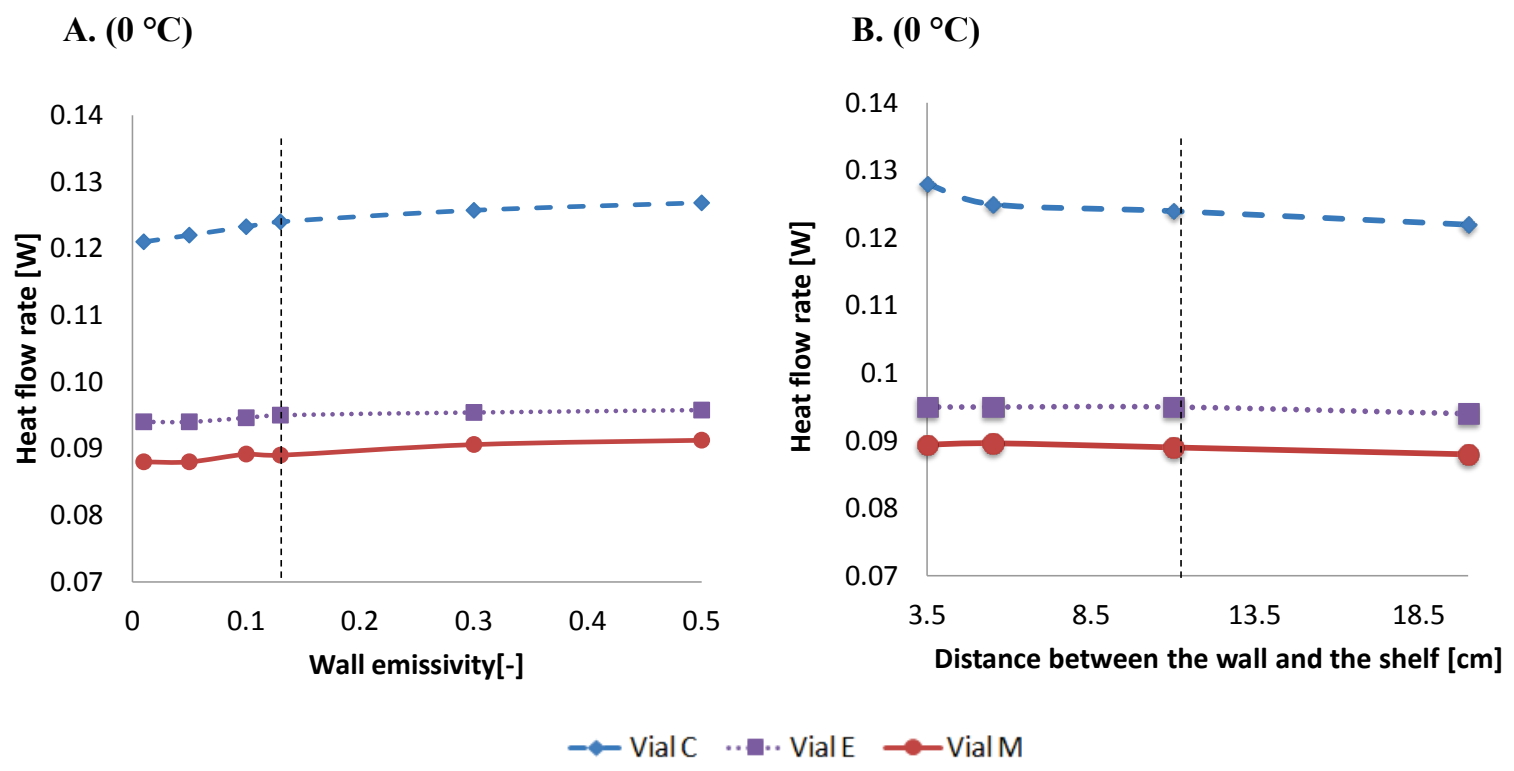

Figure 7: Heat flow rates evaluated for edge vials $\mathrm{C}$ (dashed line) and $\mathrm{E}$ (dotted line) and for central vial $\mathrm{M}$ (solid line) in the TE configuration at $0{ }^{\circ} \mathrm{C}$ and $4 \mathrm{~Pa}$ for (A) different wall emissivities and (B) distances between the wall and the shelf. Vertical dotted lines represent the values characteristic of the freeze-dryer used. TE: edge vials totally exposed to the wall. Significance of the abbreviations of vials C, E and M is reported in Figure 1. 
A. $\left(0^{\circ} \mathrm{C}\right)$

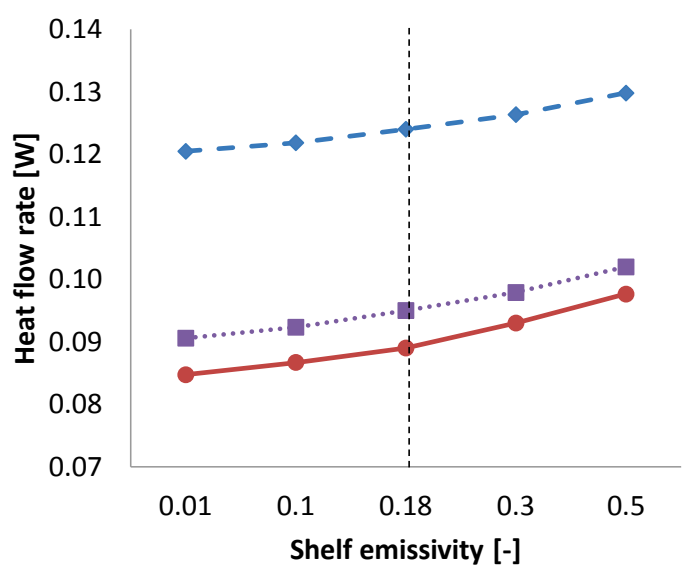

B. $\left(0^{\circ} \mathrm{C}\right)$

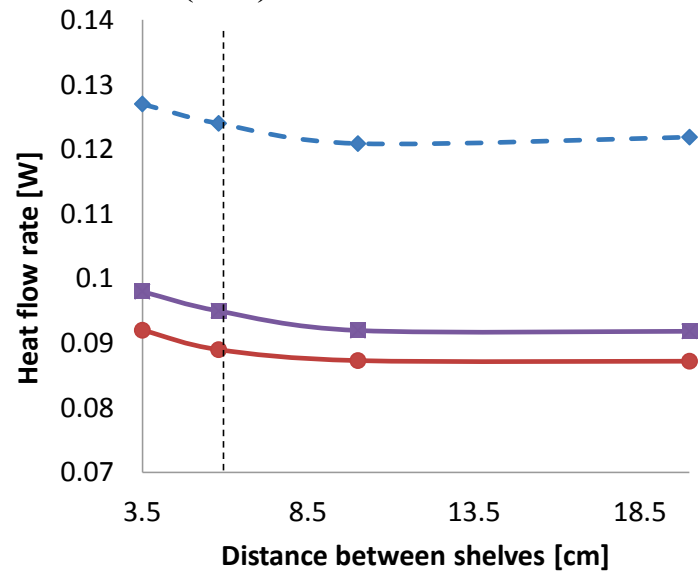

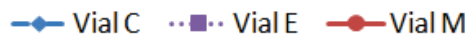

Figure 8: Heat flow rates evaluated for edge vials $\mathrm{C}$ (dashed line) and $\mathrm{E}$ (dotted line) and for central vial $\mathrm{M}$ (solid line) in the TE configuration at $0{ }^{\circ} \mathrm{C}$ and $4 \mathrm{~Pa}$ for (A) different shelf emissivities and (B) for different distances between the top and bottom shelves. Vertical dotted lines represent the values characteristic of the freeze-dryer used. TE: edge vials totally exposed to the wall. Significance of the abbreviations of vials C, E, and M is reported in Figure 1. 